\title{
RECENT EXPERIENCE IN THE MANAGEMENT OF BATTLE CASUALTIES
}

\author{
Lieutenant-Colonel W. C. MofFAT \\ M.B., F.R.C.S., D.T.M.\&H.
}

\section{Introduction}

EXPERIENCE in war surgery in these times is somewhat hard to come by and it is important that those of us who have been fortunate enough to have recent experience in dealing with battle casualties should record it for the benefit of others. Most of the points brought out in this review will be well known to all Army surgeons yet it seems important to reiterate them yet again since, in spite of a seemingly thorough knowledge of the principles of war surgery, mistakes are still made especially when "the heat is on " and large numbers of casualties require treatment within a short space of time. There is a constant temptation to modify or even abandon well tried and accepted methods and whilst this is in one sense commendable in the interests of progress it is none the less sometimes punishable by tragedy. In all of Surgery, and possibly especially in battle surgery, a heavy responsibility rests with the first surgeon to deal with the case. An error of judgement, a sin of commission, or more likely of omission, at the time of primary surgery can have far reaching consequences.

There is here reviewed the experience gained by a British Army surgeon working in an Australian Air Force Hospital in South East Asia during the 10 month period 1 st July 65 to 1st May 66. At this time an Australian Army Force was fighting in South Vietnam. The primary surgery of the casualties occurring in this force was carried out by the Medical Service of the United States Army and the cases were subsequently evacuated by air to the aforementioned Australian hospital outside the theatre of war. Second stage surgery took place here prior to repatriation.

\section{Cases}

In all 60 cases were dealt with during the period and 51 of these are here considered. They have been divided into severe, moderate and minor cases according to the severity of their wounds, and the relative numbers are seen in Table I. Severe cases are those with wounds likely to have led to death or leave much residual disability and include most cases of injury to bone, head, thorax, abdomen and major nerve or blood vessel damage. Moderate cases are those with large muscle wounds and minor fractures and minor cases are those with mainly small, although often multiple, soft tissue wounds.

Table I

\begin{tabular}{|ccc|}
\hline & Grading of Wounds & \\
\hline Severe & & 27 \\
\hline Moderate & 11 \\
\hline Minor & 13 \\
\hline Total & 51 \\
\hline
\end{tabular}


The breakdown of cases by structures involved is at Table II, and includes all cases. One patient may appear in more than one category.

Table II

Structures Injured

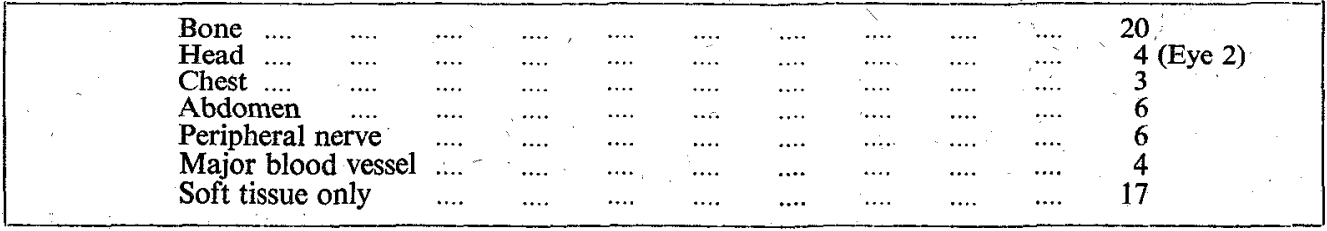

The method of wounding appears in Table HI. It will be seen that there was a high proportion of injuries due to anti-personnel (AP) mines. These were of various sorts, the commonest being a short-fused grenade filled with " rice-grain" lead pellets and fired by a trip-wire system. They produced multiple low velocity wounds mainly of the lower limbs. It is significant to note here that these injuries were often sustained in well manured " padi" country and this gave rise to problems with anaerobic infection as will be seen.

Table III

Method of Wounding

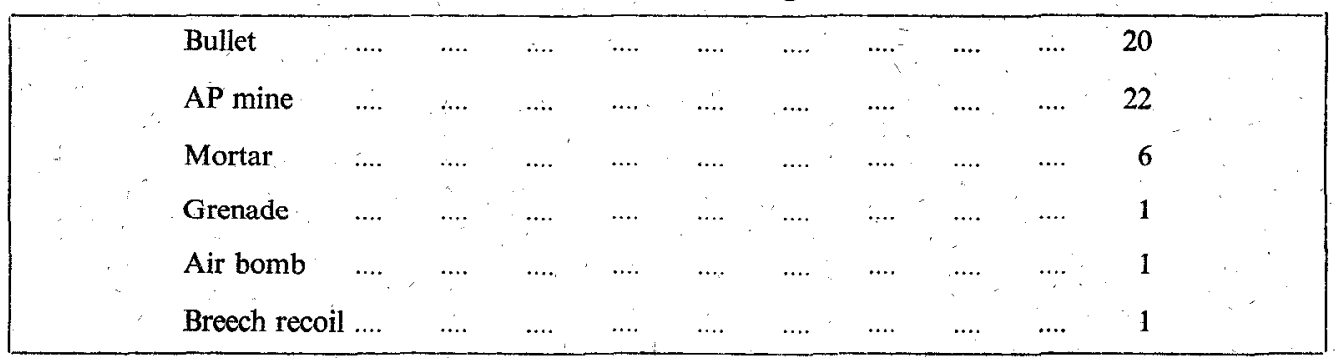

\section{Sepsis}

Serious sepsis occurred in 13 of the 51 cases, minor sepsis in 10 and 28 remained clear of clinical sepsis at all times. There were 2 cases of gas-gangrene both requiring above knee amputation, and a case summary of one of these appears later. A consideration of the development of sepsis in relation to the severity of the wound is set out in Table IV. It will be seen that 11 of 27 severe wounds developed serious sepsis whereas only 1 of 13 minor cases did so. It should be pointed out here, however, that the infecting organism was Pseudomonas pyocyanea in almost half the cases and this is likely to represent early hospital cross infection. It is evident that larger wounds are more susceptible to cross infection than smaller ones.

Table IV

Sepsis and Wound Severity

\begin{tabular}{|c|c|c|c|}
\hline Sepsis & & Wound & \\
\hline . & Severe & Moderate & Minor \\
\hline Serious & 11 & Nil & 1 \\
\hline Minor & 4 & 3 & 2 \\
\hline Nil & 12 & 8 & 10 \\
\hline
\end{tabular}


The role of early antibiotics was impossible to assess. Clear evidence of administration of an antibiotic within 2 hours of wounding was available in only 37 of the 51 cases and no accurate timings were given for these. The patients themselves were unreliable witnesses in this respect. The commonest antibiotic combination used was penicillin and streptomycin. Tetracyclines and chloramphenicol were only occasionally used. Some cases clearly given early antibiotic still developed serious sepsis and some cases with no record of having had antibiotic at any point healed cleanly.

The development of sepsis was considered in relation to the time interval before primary surgery and is tabulated in Table $V$. This time interval was in the great majority of cases commendably short. Initial casualty evacuation was almost always by helicopter. The average time to primary surgery for 35 cases where accurate times were known (it is interesting that most soldiers know the time of their wounding almost to the minute) was 4 hours. 21 cases reached primary operation in 2 hours or less and a further 8 cases between 2 and 4 hours. 2 cases took between 4 and 6 hours and only 4 cases were delayed longer than 6 hours, the longest recorded time lapse being 22 hours.

Table $\mathbf{V}$

Sepsis and Time to Surgery

\begin{tabular}{|l|c|c|c|c|}
\hline \multicolumn{2}{|c|}{ TIME LAPSE } & \multicolumn{3}{|c|}{ SEPSIS } \\
\hline 2 hours or less & 5 & Minor & Nil & Total \\
2-6 hours & 4 & 5 & 11 & 21 \\
More than 6 hours & 1 & 2 & 4 & 10 \\
\hline
\end{tabular}

These figures may seem at first somewhat surprising although it is clear the numbers in the 3 groups are not comparable and the series not big enough to draw conclusions. It is, however, probable that the more seriously injured came to primary surgery quicker and it is in some of those cases that sepsis due to cross infection tended to develop.

\section{Blood Transfusion}

Blood was used freely as reckoned against the usual expected rates for the British Army. At forward surgery available records showed that 78 pints of whole blood were given to 17 of the 51 casualties under review. This is an average transfusion of 4.6 pints and represents a transfusion rate of 156 pints per 100 cases. At second stage surgery 12 of the 51 cases received 68 pints of whole blood, an average transfusion size of 5.6 pints and an extrapolated transfusion rate of 136 pints per 100 cases. Thus the combined expected transfusion rate for whole blood to cover both first and second stage surgery approaches 300 pints per 100 casualties.

8 cases initially transfused at first stage surgery with a total of 33 pints of whole blood were further transfused at second stage surgery with a total of 47 pints of whole blood. This was done to correct the haemoglobin level to $11 \mathrm{G} / 100 \mathrm{ml}$ and maintain it 
there or as near there as was possible or practicable. It is well known in accident surgery that the haemoglobin level of the seriously injured will tend to fall off in the few days following injury even if apparently adequate blood replacement is made at the time of injury, and it is further recognised that it is well worth " topping-up " with further whole blood to speed recovery, encourage wound healing and combat infection.

Many of the important points to be remembered in the management of battle casualties are illustrated in the following case summaries.

Case No. (1)

075 Pte R. M. (Serial No. 17): Aged 25.

Whilst acting as a forward scout he was wounded by an anti-personnel mine at 1300 hours 12 October 65. He sustained multiple wounds of both lower limbs with open fracture of mid-shaft of (R) femur and open fracture of upper (R) tibia. Primary surgery was carried out at 1430 that day and consisted of debridement and irrigation of the wounds. A Steinmann pin was inserted through the (R) os calcis and a full length (R) hip spica applied. He was given 7 pints of whole blood and penicillin. He was evacuated by air to second stage surgery outside the war zone where he arrived at 2300 hours 13 October 65 in poor general condition, apprehensive and toxic. Further transfusion with whole blood was commenced and he was taken to theatre as soon as possible. The (L) leg was found to be affected by gas-gangrene. It was avascular below the knee, discoloured, smelt sickly and sweet and bubbles could be easily expressed from multiple small but deep wounds in the leg. In the $(R)$ lower limb there was a large open wound from thigh to calf posterolaterally and it communicated with the fractures of femur and tibia. There were also multiple small wounds below the knee, all widely open. All the wounds of this limb seemed clean, and there was no evidence of anaerobic infection in this limb. An above knee amputation was carried out at the site of election on the (L) side leaving the flaps open to drain. The full length $(R)$ spica was reapplied after redressing the wounds. He was given 3 pints of whole blood and started on methicillin 1G 6 hourly and streptomycin $1 \mathrm{G}$ bd. Anti gas-gangrene serum was not used.

His condition in the period immediately following operation was good but 12 hours later he was again very toxic. This, however, rapidly settled without change of therapy and by 15 October 65 he was looking and feeling much better. Stump dressing done on 17 October showed the amputation wound to be clean and it was sutured. On 19 October although his general condition remained good his $(R)$ foot was noted to be red and slightly swollen. He was taken to theatre and the spica removed when the antero-lateral compartment of the leg was seen to be heavily infected. Gas bubbles were present in the wounds and the muscle could be seen to be dead although grey rather than brick red. It was felt that this was anaerobic cellulitis rather than further true gas gangrene. The whole compartment was widely opened from knee to ankle and all diseased muscle removed - all of tibialis anticus and most of the peronei. The thigh wound looked superficially infected only. He was given a further 4 pints of whole blood and methicillin and streptomycin were continued in full doses. The spica was discarded in favour of a Thomas splint with a little fixed traction only.

His general condition remained good until 2 days later when, on 21 October, he " collapsed " with rapid pulse and low blood pressure due to secondary haemorrhage from the wound of the (R) thigh. He was further transfused with 6 pints of blood in all during the operation to tie the profunda femoris artery which was the source of the bleeding. Thereafter his progress was not very remarkable. The (L) thigh stump healed well.

The wound of the $(R)$ thigh was largely closed in its deeper part but remained surface infected and could not be grafted early. The leg wound was sutured secondarily but broke down in part. The fractures remained in good position in the Thomas splint and this was made into a Tobruk plaster for repatriation by air on 13 November 65 .

He was examined personally in Australia on 16 March 66. His general condition was excellent and he was well adjusted to his amputation and was to be measured for a prosthesis in a few days' time. His wounds had healed and the fractures had united although he had not yet taken weight on the limb. Photographs subsequently seen have shown him standing without the aid of crutches and latest information states that he is now walking unaided-11 months from the time of wounding.

Case No. (2)

775 Pte R. K. Mc (Serial No. 15): Aged 20.

This patient was wounded at 1500 hours on 12 October 65 by a bullet which entered the $(L)$ hip area anteriorly and penetrated the abdomen. Primary surgery was carried out at 1730 hours that day consisting of wound debridement and laparotomy at which 3 feet of damaged small bowel were resected and a wound of the caecum repaired. A (L) flank colostomy was established and the abdomen closed with drainage. He was given 16 pints of whole blood of Group O NEG (he was Group O POS) and tetracycline intravenously. This was changed to I.M. chloramphenicol after 24 hours and penicillin and streptomycin were added also then. He was evacuated by air on 15 October 65 only 3 days after wounding and arrived at second stage surgery having had a very uncomfortable plane trip with considerable abdominal pain and in poor general condition. He was markedly jaundiced with serum bilirubin of $11 \mathrm{mgms} / 100 \mathrm{mil}-9$ mgms of which was indirect reacting indicating a haemolytic jaundice. Haemoglobin was $12 \mathrm{G} / 100 \mathrm{ml}$ $(85 \%)$. 
After a somewhat difficult period stabilizing his fluid and electrolyte balance and persuading his colostomy to work well his general condition improved remarkably but his haemoglobin continued to fall and he was matched for 4 pints of blood. This blood was compatible after a full standard 2 hour technique. It was not, however, given until 48 hours after matching when his haemoglobin had fallen to $10 \mathrm{G} / 100 \mathrm{ml}$. After only about one quarter of a pack of blood he felt unwell and had a rigor and transfusion was immediately stopped. In spite of this in the ensuing 2 days his jaundice became much deeper clinically and the serum bilirubin rose to $13 \mathrm{mgms} / 100 \mathrm{ml}$ almost all indirect reacting. Thereafter no further attempts to transfuse were made and he made good progress being repatriated ambulant on 13 November 65 .

\section{Case No. (3)}

994 Tpr R. L. J. (Serial No. 32): Aged 25.

This patient was wounded 1830 hours on 21 February 66 by a sniper's bullet which passed through his (L) leg causing an open fracture of the tibia with much bone destruction and initial bone loss. Primary surgery was carried out at 1900 hours that day and consisted of wound debridement. The wound was left widely open and lightly dressed and a back slab applied to maintain alignment. He was given 1 pint of whole blood and 4 pints of plasma. There was no record of his having had any antibiotic.

He was admitted to second stage surgery on 26 February 665 days after wounding in good general condition with haemoglobin level of $10.8 \mathrm{G} / 100 \mathrm{ml}(72 \%)$. Theatre dressing the following day revealed a large open wound from just below the knee to 4 finger breadths above the ankle joint and involving the entire anterior aspect of the leg. The fluffed gauze dressings had been stained and were a little smelly but the wound itself was clean. The fracture of the tibia was clearly visible in the middle of the wound there being a gap between the bone ends of at least $1^{\prime \prime}$ when the limb was held out to length. Skin loss made delayed primary suture (D.P.S.) impossible and clearly a split skin graft had small chance of survival until the wound was stabilized by holding the tibial fracture. It was decided to do this by employing an external skeletal fixation device and such a device was made in the local Australian Air Force workshop. It consisted of 4 clamps for attachment to Steinmann pins with an interconnecting steel rod for each side of the leg. The device was ready for use in 5 days and on 4 March operation was undertaken.

Two Steinmann pins were passed parallel to each other about $1 \frac{1}{2}$ apart through each of the main proximal and distal tibial fragments. With the clamps attached to their ends and the interconnecting rods in place the relative positions of the tibial fragments could be controlled in all three planes and good alignment was achieved and maintained whilst allowing the gap to remain and holding the bone to length ready, it was hoped, for bone grafting when wound healing had been achieved. After "fixation "-and it should be clearly stated that there was no metal at the fracture site itself-the leg was very comfortable and the patient could move his knee and to some extent his ankle. On 10 March the wound was inspected and found clean and a split skin graft was applied. This took well and the patient was repatriated still in the device on 3 April 66 able to flex his knee to $90^{\circ}$. It was subsequently reported that a cross leg flap was successfully done with his initial fixation device in place, and the leg was ready for bone grafting by late August 66.

\section{Discussion}

The lessons to be learned from a consideration of these cases are self evident. The penalty for failure to carry out a thorough primary wound debridement is high. A minor wound may become a major problem, and such minor wounds may co-exist with serious injury elsewhere in the same patient. The latter tends to take a large amount of the operating time available to a hard pressed forward surgical team and the benefits of thoroughness must be weighed against the dangers of delay in treating other patients. Sorting of cases into priorities for surgery becomes of prime importance at such a time and this is a task which requires considerable knowledge and experience. The successful management of established anaerobic infection requires swift decisive action and an approach bordering on ruthlessness. Adequate surgery combined with high dosage of appropriate antibiotics and blood transfusion can be successful alone and anti gasgangrene serum need not be, and should not be, used. Consideration should be given to the possibility of employing a compression chamber for the administration of hyperbaric oxygen. This was done in Case No. (1) and it was found that the Royal Navy were in possession of small portable one-man chambers which seemed entirely adequate for the purpose.

The Thomas splint is still an outstanding success and the Tobruk plaster a most valuable means of protecting the injured lower limb in transit. The hip spica is heavy, cumbersome, uncomfortable, often soiled and may hide important developments in the wounded parts. 
Case No. (2) shows that it is still unwise to transport the recent abdominal wound even by air and it further illustrates the danger of massive transfusion with whole blood which, although compatible, is not of the patient's own group. The need of the moment will of course take priority over all else but such a patient beárs careful watching especially if further transfusion is needed, and most certainly there should not be delay between cross matching and giving such blood.

Case No. (3) illustrates how successful good initial surgery can be. Given a clean healthy wound, however large and however initially alarming the situation may seem to be, the tasks of secondary and definitive surgery are tremendously eased. This patient shows to advantage what is perhaps the greatest principle in the field of the surgery of trauma - put healthy tissues together and they will heal.

\section{Conclusion}

The principles of war surgery as at present understood are sound and success in the treatment of battle casualties will be proportionate to the thoroughness with which they are applied.

Further research is needed into two aspects of management. First, the necessity for early administration of antibiotics needs to be proved beyond reasonable doubt, and second, we must carefully consider the possibility that present estimates of blood required for battle casualties may be too low.

\section{ACADEMIC ACHIEVEMENTS}

F.R.C.S. (in Otology) MAJOR P. G. A. BLOOMER, M.B., B.Chir., D.L.O., R.A.M.C.

M.R.C.O.G.

MAJOR B. BETHELL, M.B., Ch.B, D.Obst.R.C.O.G., R.A.M.C.

D.Obst.R.C.O.G.

D.P.M.

CaPTATN E. J. KING, M.B., B.S., M.R.C.S., L.R.C.P., D.T.M.\&H., R.A.M.C.

Major P. J. CALlaGHAN, B.A., M.B., B.Ch.; B.A.O., R.A.M.C.

MAJOR P. D. W. WICKENDEN, M.B., B.Chir., D.Obst.R.C.O.G,, R.A.M.C.

D.M.R. (Part II) CAPTAIN P. R. CAMM, M.B., B.S., M.R.C.S., L.R.C.P., R.A.M.C.

CAPTAIN W. H. LEACH, M.B,, Ch.B., D.T.M.\&H., R.A.M.C.

\section{Doctor of Philosophy}

This degree was conferred on Lieutenant-Colonel James Mills Adam, R.A.M.C., on 14th September, 1966, in the Faculty of Medicine in the University of London in the field of study of Human Physiology.

It is comparatively rare for this degree to be obtained in the Faculty of Medicine and by a serving officer.

\section{Honorary Consultant}

Professor A. L. D'Abreu (Honorary Consultant Thoracic Surgeon to Ministry of Defence-Army) has been appointed McLaughlin Foundation Edward Gallie visiting professor to the Royal College of Physicians and Surgeons of Canada. 